\title{
Aggregate and Regional Economic Effects of New Railway Infrastructure
}

\author{
WOLFGANG POLASEK* \\ Institute for Advanced Studies, Vienna \\ WOLFGANG SCHWARZBAUER \\ Institute for Advanced Studies, Vienna \\ RICHARD SELLNER \\ Institute for Advanced Studies, Vienna
}

\begin{abstract}
Economists expect positive returns to investments in infrastructure. However a project with higher national returns might have less favorable effects on a regional level than the alternative. Therefore new infrastructure should also be assessed on a regional level, but econom(etr)ic evaluation models are scarce, especially in regional science. This paper proposes new approaches to evaluate infrastructure by a dynamic spatial econometric model that allows long-term predictions. We investigate the regional effects for 2 Austrian railway projects and show that infrastructure returns are positive on an aggregate and at a regional level, and spatial variation can be large.
\end{abstract}

Keywords: Regional growth convergence, traffic accessibility, infrastructure evaluation, spatial econometrics.

JEL Classifications: C31, H43, H54, R11, R12

\section{Introduction}

Investments in infrastructure is expensive and economists have argued for a long time about measurable economic effects of infrastructure. Aschauer (1989) investigated the effects of public infrastructure following a production function approach and found the social rate of return of public infrastructure to be substantial. It should be noted however that this study was based on national level data, whereas studies conducted on the regional or metropolitan area levels found much smaller effects (compare ECMT, 2000). This may be due to the fact that the regional level effect of improving traffic infrastructure is more or less ambiguous on this level. This can be explained by the New Economic Geography literature, which stresses the role of centrifugal and

*Corresponding author: IHS, Stumpergasse 56, A-1060 Vienna, e-mail: polasek@ihs.ac.at, Phone: +43-1-59991155, Fax: +43-1-59991163

(C) 2010 Wolfgang Polasek, Wolfgang Schwarzbauer, and Richard Sellner. Licenced under the Creative Commons Attribution-Noncommercial 3.0 Licence (http://creativecommons.org/licenses/by-nc/3.0/). Available at http://rofea.org. 
centripetal forces. An improvement of infrastructure and therefore a decline in transportation costs will on one hand benefit the firms in a core area by enlarging their market, on the other hand benefit the firms in remoter areas by increasing their competitiveness. (Krugman, 1991).

The literature on the assessment of improving the infrastructure or building new infrastructure is based on growth accounting approaches (Baum \& Kurte, 2001), CGE modelling (compare Broecker et al., 2004, Steininger et al., 2007) as well as econometric modelling (Lall, 2007, Polasek \& Schwarzbauer, 2006).

In this paper we follow an econometric approach, as we want to test whether infrastructure improvements will also lead to improvements in economic performance, measured by GDP, firms and employment. The variable used to identify the improvement in traffic infrastructure is accessibility of regions. Accessibility is believed to be one of the main engines of economic activities, for countries as well as for regions. Surprisingly, there is little empirical evidence that shows the connection between accessibility and regional growth. This paper demonstrates that modern spatial econometrics allows modelling this missing link between regional economic indicators, like GDP, employment and firm growth, and rail traffic. In addition to that we show that infrastructure can have different effects on a regional and a national levels. Our model approach allows us to forecast on both levels so that the aggregate infrastructure effect can be broken down and their regional distribution can be assessed. This allows to analyse the question whether new infrastructure will hamper or foster regional economic convergence. As will be shown later effects in both directions can be observed when new infrastructure is available for use.

We will describe a dynamic model that builds on regional data for the period 1995-2005 for 99 Austrian regions (politische Bezirke). We have called this model EAR (economic accessibility and regional) model, because we model regional growth as a function of infrastructure, regional economic indicators, demographics, and traffic related accessibility. Until recently, the data base on a regional level was quite unreliable, even more so for smaller units. But our analysis shows that it is possible to explore economic relationships at a finer level, like political districts $^{1}$, as it was not possible in the past.

In this application of the Austrian EAR model we will focus on 3 regional economic indicator: GDP growth, employment growth and firm growth. For all of these indicators we will estimate a dynamic panel model and make a 30-year prediction, where we use next to the dynamic behavior of the model the improved accessibility as a major stimulus of future growth.

While the general model can discriminate between train and road accessibility and between short-distance and long-distance accessibility, we will focus in this application on train accessibility. Since train accessibility is a quite general concept, we tried to focus this type of accessibility on three more traffic related features: a) travel times, b) frequency of connections,

${ }^{1}$ Political districts do not follow the official Eurostat regional classification. They are subregions of Austrian NUTS-3 regions and are administrative Austrian regional units. 
POLASEK, SCHWARZBAUER, SELLNER Effects of new railway infrastructure

and c) traffic volume. With this additional information we were able to construct the sensible accessibility variables that connect to the economics indicators that are the focus variables in the EAR model. Interestingly, as the estimation results show, different accessibility indices are driving the economic activities in the Austrian regions.

This paper is organized as follows. Section 2 introduces the model and the concept of accessibility. Section 3 presents and discusses the model estimated and used. Section 4 presents the simulation results for two infrastructure projects and distinguishes between regional and aggregate effects. A final section concludes.

\section{The Model}

Infrastructure is an important factor for economic growth and development of a region. A welldeveloped infrastructure ensures mobility of production factors within and across economies and should lead to a more efficient allocation and utilization of resources. Demographic structures are an important determinant for regional developments, as e.g. in regions with an older population we cannot expect a high population growth. Another feature of the regional structure is the firm and population density. On average the prices of land in a region that is more densely populated will be higher. As a consequence the costs of establishing a firm will be higher in more densely populated areas.

\subsection{Specification of the Model}

In a first step, all the potentially influential variables are included into a set of candidate variables for a BMA (Bayesian Model Averaging) analysis in a linear model, (see also LeSage and Parent, 2006 for spatial extension) to select the most probable model from this set. The set of variables has included dummy variables, regressors and their spatial lags, where different weight matrices $\mathrm{W}$ based on travel times were used and the accessibility indicators. The weight matrices $\mathrm{W}$ we used included distances, travel times and nearest neighbors.

Given the selected (i.e. most probable) variables from a BMA analysis, the final model for each variable is estimated using Bayesian routines and estimators. We estimate a Bayesian heteroskedastic linear model using a hierarchical model for the variance inflation factors of the observations (see Geweke, 1993) together with a spatial autoregressive model as in LeSage (1997) based on the results of the BMA analysis. ${ }^{2}$ The ordinary linear model is given by the following equation

$$
\Delta y_{t}=c+A I_{t} \alpha+\Delta X_{t} \beta+\epsilon_{t}
$$

\footnotetext{
${ }^{2}$ For the estimation procedure we used the Econometric Toolbox for Matlab by J.P. LeSage (see LeSage, 1997 and http://www.spatial-econometrics.com).
} 
where where $\Delta y_{t}$ is the difference of the logged dependent variable (i.e. either cross-sectional GDP, employment or number of firms) at time t, $c$ is a constant. $A I_{t}$ is the matrix containing the selected set of accessibility indicators, $\Delta X_{t}$ is the matrix of differences of the log of other explanatory variables included in the regression, and $\epsilon_{t}$ is the vector of errors that are assumed to be heteroskedastic: $\epsilon_{i, t} \sim N\left(0, v_{i} \sigma^{2}\right)$. For the inverse elements of the variance inflation factors $v_{i}$ we assume a standardized $\chi^{2}$-distribution with $r$ d.f., i.e.

$$
\begin{aligned}
v_{i}^{-1} & \sim \chi^{2}(r) / r \sim G a_{1}\left[v_{i}^{-1} \mid 1, r\right] \\
r & \sim G a_{1}\left[v_{*}, \lambda_{*}\right] .
\end{aligned}
$$

We also tested for SAR model specifications, however, the non-SAR specifications with AI indicators provided the best description of the data used for this analysis.

\subsection{Accessibility}

Polasek (2005) shows for central European countries that travel time improvements and reduced transport costs will have positive effects on the growth of these regions.

Although it is a popular argument in regional economics, accessibility is difficult to measure directly ba single variable and can only be approximated in an econometric model. (Also, see Schuermann \& Talaat, 2000, or Spiekermann \& Neubauer, 2002 for a discussion on accessibility indicators and concepts.) In this paper accessibility will be proxied in several ways. First of all, we will distinguish between train and roads and between short-distance and long-distance accessibility indicators. In general, there are three dimensions or special characteristics to accessibility:

\section{Travel Times}

Travel time is a central feature of accessibility as it is often related to either time or monetary costs for firms and for private persons.

\section{Frequency of connections}

As in supply-driven public transport systems, like the railways, the number of connections from one region to another is important for its accessibility.

\section{Volume}

The transport volume can be regarded as an indicator for the attractiveness of a region. Concerning goods transport volumes the flows between regions are an indicator of the market integration of these regions.

To implement the concept of accessibility in an econometric model, so-called accessibility indicators are constructed. The aim is to provide a set of indicators that can cover most of the aspects of the economic notion of accessibility. Let $\mathbf{A}=\left(a_{i j}\right)$ be a positive quadratic travel 
POLASEK, SCHWARZBAUER, SELLNER Effects of new railway infrastructure

time matrix with $i=1, \ldots, N$ and $j=1, \ldots, N$. The distance between the $\mathrm{n}$ regions is given in matrix $\mathbf{B}=\left(b_{i j}\right)$; on the main diagonal there are only zero entries. (Each element of matrix A corresponds to an entry in matrix $\mathbf{B}$ and has the same dimension.) Using these two matrices, an indicator, which summarizes the accessibility of region $i$, can be calculated in the following way:

$$
A I_{i}=\sum_{j=1}^{N} a_{i j} \omega_{i j}, \text { where } \omega_{i j}=\frac{b_{i j}}{\sum_{j=1}^{N} b_{i j}}
$$

The weights $\omega_{i j}$ are normalised across rows and measure the relative distance of regions $i$ and $j$ in comparison with other regions. A large value of $A I_{i}$ in region $i$ is a bad indicator. This can be explained by considering two pairs of regions with the same distance between them $\left(b_{i j}=b_{i^{\prime} j^{\prime}}, i \neq i^{\prime}\right.$ and $\left.j \neq j^{\prime}\right)$ then the travel time can be different $\left(a_{i j} \neq a_{i^{\prime} j^{\prime}}\right)$, especially if the traffic infrastructure between the regions is different.

Table 1: Train Accessibility Indicators (AI)

\begin{tabular}{|c|c|c|c|}
\hline no. & name & Accessibility & Weight \\
\hline 1 & $A I_{1}$ & Accessibility Far & $\omega_{i j}=\frac{b_{i j}}{\sum_{j=1}^{N} b_{i j}}$ \\
\hline 2 & $A I_{2}$ & Accessibility Near & $\omega_{i j}=\frac{\frac{1}{b_{i j}}}{\sum_{j=1}^{N} \frac{1}{b_{i j}}}$ \\
\hline 3 & $\mathrm{AI}_{3}$ & Frequency-weighted Accessibility Far & $\omega_{i j}=\frac{f q_{i j} b_{i j}}{\sum_{j=1}^{N} f q_{i j} b_{i j}}$ \\
\hline 4 & $A I_{4}$ & Frequency-weighted Accessibility Near & $\omega_{i j}=\frac{f q_{i j} \frac{1}{b_{i j}}}{\sum_{j=1}^{N} f q_{i j} \frac{1}{b_{i j}}}$ \\
\hline 5 & $A I_{5}$ & Volume-weighted Accessibility Far & $\omega_{i j}=\frac{\operatorname{vol}_{i j} b_{i j}}{\sum_{j=1}^{N} \operatorname{vol}_{i j} b_{i j}}$ \\
\hline 6 & $A I_{6}$ & Volume-weighted Accessibility Near & $\omega_{i j}=\frac{\operatorname{vol}_{i j}}{\sum_{j=1}^{N} \operatorname{vol}_{i j} \frac{1}{b_{i j}}}$ \\
\hline
\end{tabular}

Table 1 shows the different accessibility indices based on different weighting schemes, which we will be used in the EAR model. Note that long-distance indices (i.e. $A I_{1}, A I_{3}$ and $\left.A I_{5}\right)$ use distances as weights while the local accessibility indices (i.e. $A I_{2}, A I_{4}$ and $A I_{6}$ ) are calculated with the inverse weights of the long-distance accessibility indicator. 
Apart from ordinary, frequency-weighted and volume-weighted indicators a further indicator was constructed to capture to connection of a location to a supra-regional center, which in our case are the capitals of NUTS- 2 regions. ${ }^{3}$. However the explanatory power of this indicator proved to be rather poor. As a consequence it was not included in the model.

In addition to train based travel times we also include road based travel times, where $A I_{7}$ corresponds to $A I_{1}, A I_{8}$ corresponds to $A I_{2}$ but using road instead of train travel times.

\subsection{Data Base}

Data on firms and employment have been obtained from 'Statistik Austria' for the period 19982005 (report on 'Leistungs- \& Strukturerhebung'). GDP data have been broken down to the 99 political districts from NUTS-3 level GDP by tax statistics. Travel times, connecting frequencies and individual traffic volumes as well as their changes have been provided by the Austrian federal railways (OeBB). Rail cargo volumes between the 99 political districts were obtained from the Statistik Austria for various years. The regional units in our analysis are the 99 Austrian political district.

\section{Estimation Results}

By applying Bayesian model averaging to the data set we selected the model with the highest posterior density and estimated a Bayesian heteroskedastic linear model (see Geweke, 1993) if the spatial lag was not included in the model and the spatial autoregressive model (see LeSage, 1997) in the other case. We found that in general the explanatory power of ordinary linear models provided the better description of the data, as the spatial lag was almost never significant and the effect of it was negligible. To further refine the estimates we dropped insignificant variables to obtain the following system of equations for GDP (gdp), employment (emp) and the number of firms (firm):

$$
\begin{aligned}
\Delta g d p & =c_{1}+\alpha_{1,2} a i_{2}+\alpha_{1,7} a i_{7}+\alpha_{1,8} a i_{8}+\beta_{1,1} \Delta g d p_{t-1}+\gamma_{1} D U_{1}+\epsilon_{1} \\
\Delta e m p & =c_{2}+\alpha_{2,2} a i_{2}+\alpha_{2,7} a i_{7}+\alpha_{2,8} a i_{8}+\beta_{2,1} W \Delta g d p_{t-1}+\gamma_{2} D U_{2}+\epsilon_{2} \\
\Delta f i r m & =c_{3}+\alpha_{3,2} a i_{2}+\alpha_{3,5} a i_{5}+\alpha_{3,8} a i_{8}+\beta_{3,1} \Delta \text { firm }_{t-1}+\gamma_{3} D U_{3}+\epsilon_{3},
\end{aligned}
$$

where all small letters are variables in $\operatorname{logs}, c_{i}$ is the constant in the respective equation and $\epsilon_{i}$ are the error terms of the respective equations. Each equation contains a different number of dummy variables for NUTS-2 regions to capture different growth of regions in different NUTS-2 regions as probably driven by different incentives for setting up of firms, employment creation and general factors that might affect the development of regional GDP. This system was estimated equation by equation. Table 2 present the estimation results of the model.

${ }^{3}$ For the states of Lower Austria and the Burgenland two different sets of this indicator were used, either using the respective capitals of the states (Bundesland) or using Vienna as a central location in Austria. 
POLASEK, SCHWARZBAUER, SELLNER Effects of new railway infrastructure

Table 2: Estimation Results

\begin{tabular}{lccc}
\hline \hline \multicolumn{3}{c}{ Dependent Variable } \\
& $\Delta g d p$ & $\Delta$ firm & $\Delta e m p$ \\
\hline$A I_{1}$ & - & - & - \\
$A I_{2}$ & $-0.3^{* * *}$ & $-0.065^{* * *}$ & $-0.041^{* * *}$ \\
$A I_{3}$ & - & - & - \\
$A I_{4}$ & - & - & - \\
$A I_{5}$ & - & - & $-0.029 * * *$ \\
$A I_{6}$ & - & - & \\
$A I_{7}$ & $0.046^{* * *}$ & $-0.690^{*}$ & - \\
$A I_{8}$ & $-0.180^{* * *}$ & $0.074^{*}$ & $0.087^{* * *}$ \\
$\Delta g d p_{t-1}$ & $0.522^{* * *}$ & & \\
$\Delta$ firm & - & - & $0.226^{* * *}$ \\
$W * \Delta g d p_{t-1}$ & - & $0.178^{* *}$ & - \\
\hline R-sq. & 0.32 & 0.42 & 0.4 \\
Obs., Var & 99,12 & 99,15 & 99,15 \\
N.draws & 150000 & 150000 & 150000 \\
N.omit & 1500 & 1500 & 1500 \\
\hline \hline
\end{tabular}

Notes: $* * *, * * *$ denotes significance at the $1,5,10 \%$ level. $W$ : inverse train travel times, 0 entries on the main diagonal, row normalized; the coefficient estimates for the constant and NUTS-2 dummies are not shown here; the firm and employment equation include dummies for all 8 NUTS-2 regions for reasons explained above; in the GDP equation we dropped the NUTS-2 dummy for Lower Austria and Vorarlberg as these were almost never chosen by the Bayesian model averaging procedure and therefore displayed the smallest marginal posterior probability

GDP growth reacts to the unweighted near accessibility railroad indicator, so does firm growth and employment growth. A significant influence could also be observed for the unweighted travel time accessibility on the road. Note that for the accessibility indicators a negative elasticity implies positive effects, as a negative change in the indicator implies an improvement in accessibility. For GDP growth a significant time lag was also found to influence contemporaneous GDP growth. Lagged neighboring GDP growth was found to be a determinant of firm growth. This means that if GDP growth accelerated in the past in neighboring districts, firm growth would also accelerate in the subsequent period. The spatial dependence was modeled using inverse travel times between the districts. For employment growth we find that firm growth appeared to be of a positive influence. 


\section{Simulation}

In this section we use the estimated model to simulate the effect of two major train infrastructure improvements in Austria. The first subsection will present the general results of the two projects, whereas the second subsection will discuss the simulation results by comparing it to the past growth performance of the 99 Austrian political districts. Thus we are able to explain whether this infrastructure improvements lead to more or less convergence among Austrian regions.

The data for travel time improvements were provided by the Austrian federal railways (OeBB). Using these data we were able to determine the accessibility improvements (i.e. changes in the accessibility indicators), which were then used to shock the system of three equations in our system and simulate GDP, employment effects as well as the effect on the number of firms in each region.

\subsection{General Simulation Results}

In this subsection we present the simulation results for two main train infrastructure improvements, the tunnel project Semmering Basistunnel (SBT) and the Vienna central train station (VIE central).

Figure 1 displays the effects of the operation of the Semmering tunnel as well as Vienna central station on a national level. As Aschauer (1989) and other authors would argue, the effect of new infrastructure increases only the level and not the growth rate of the Austrian economic performance, measured by the level of employment and the number of firms. The two top diagrams show the effect on cumulated firm and employment growth for the Vienna central station, the two lower diagrams the effect on employment \& firm growth in the case of the Semmering tunnel. According to the model launching the Semmering Basistunnel would increase the level of Austrian firms by 0.65 percent and employment by 0.0023 percent. In contrast to that launching Vienna central station would increase the number of Austrian firms by 1.1 percent and Austrian employment by 0.003 percent in the long run. The effect materializes almost completely in the first ten years of operation.

Disaggregating the effects to regional levels reveals that the regional pattern is completely different in the two projects, which can be seen in figure 2. The Semmering tunnel, which is along the southern railway line in Eastern Austria would positively impact the regions in North-Eastern (greater Vienna region) and Southern Austria (the NUTS-2 regions Styria and Carinthia). From the new Vienna central station regions in the north-east and along the Western railway lines would benefit. As these two examples demonstrate it is important to look at the inter-regional distribution of the effects of new infrastructure. 
POLASEK, SCHWARZBAUER, SELLNER Effects of new railway infrastructure

Figure 1: Cumulative Effects on the Number of Firms and the level of Employment.
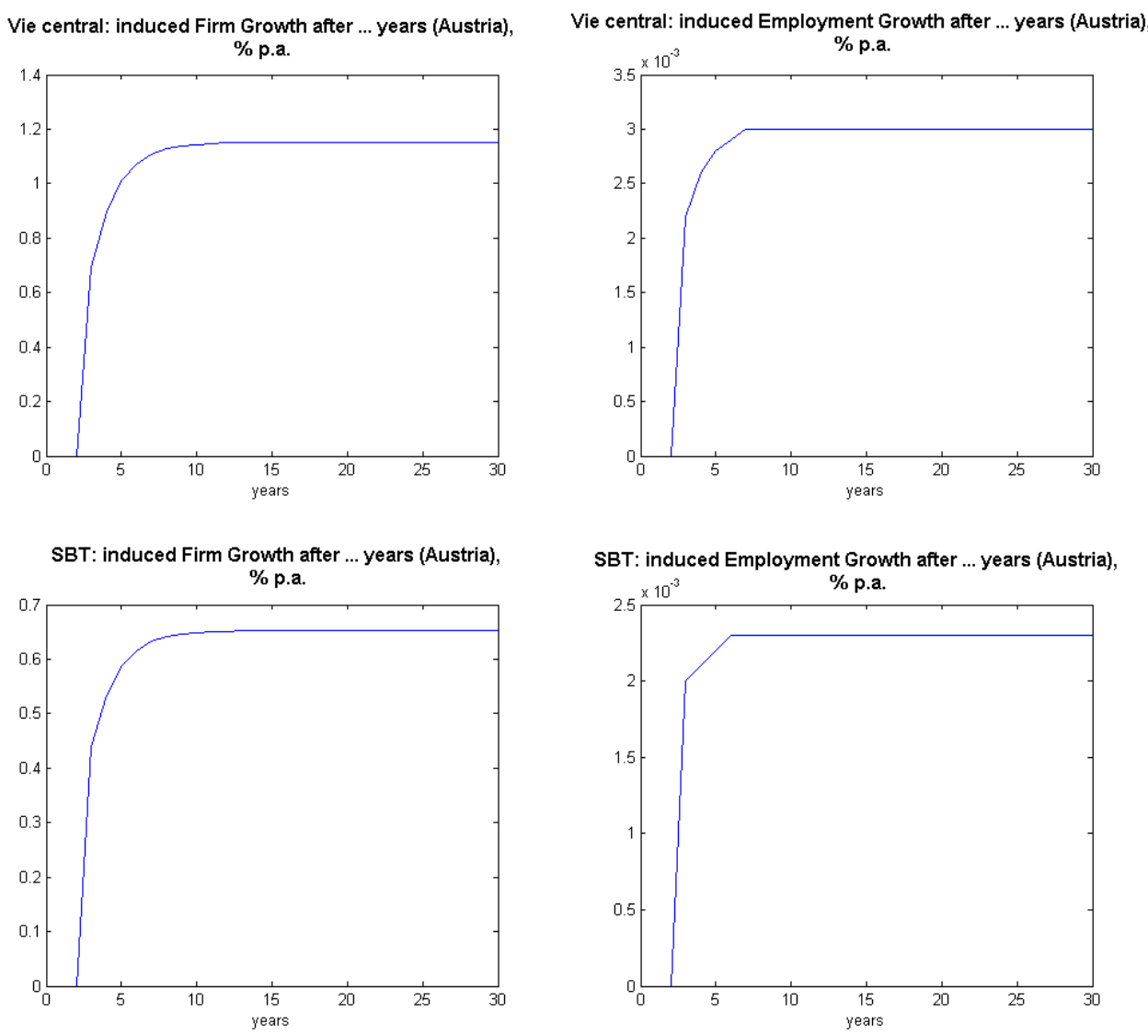

\subsection{Infrastructure and Regional Convergence}

The question that can now be addressed is which project is better in helping less developed or structurally weak regions in improving their economic performance. As infrastructure projects impact regions differently, they will potentially foster convergence or increase divergence of economic activity.

The classification of structurally weak regions is done along two variables: regional unemployment and per-capita gross regional product. To identify structurally weak regions we split the sample into two groups with less/more than average Austrian GDP per capita. Apart from this we also look at regional unemployment and compare a particular region's unemployment rate with the Austrian average. According to these two criteria we are able to identify regions with high unemployment and low levels of GDP per capita, which are defined as struc- 
Review of Economic Analysis 2 (2010) 73-85
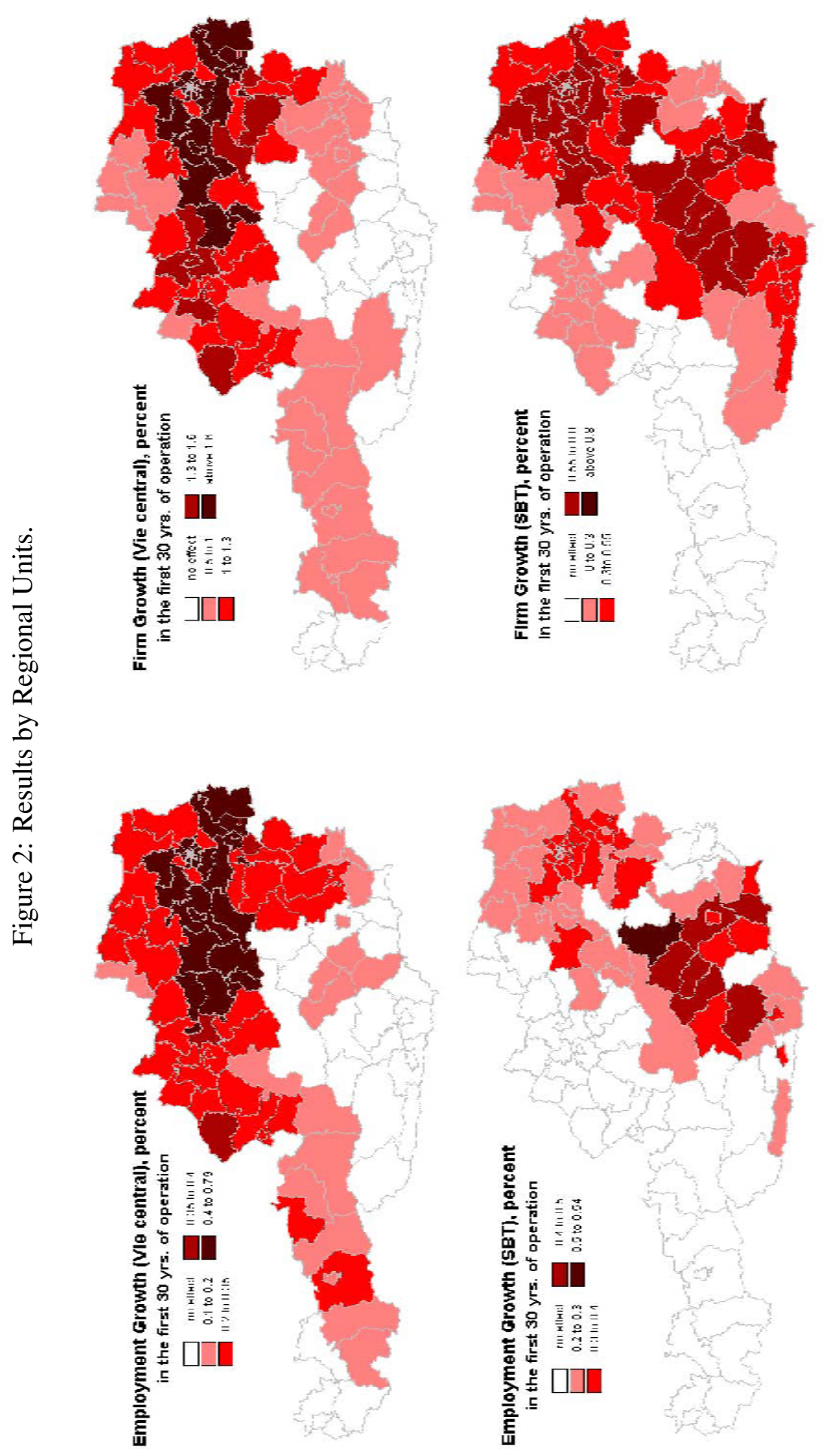
POLASEK, SCHWARZBAUER, SELLNER Effects of new railway infrastructure

turally weak regions. This enables us to assess whether those regions will benefit more than regions with relatively low unemployment and high levels of GDP. If this is the case the infrastructure project fosters convergence among Austrian regions.

This can done by correlating the induced employment effects and past unemployment rates and induced GDP effects and past GDP per capita. In the first case we would observe a positive correlation between employment effects and unemployment rates indicating that most of the new jobs are being created in regions with high unemployment, if the infrastructure project fosters convergence. For the latter case we would observe a negative correlation indicating that most of the new economic activity in concentrated in regions with low GDP per capita. The results for the two projects are presented in Figure 3.

We can observe for Vienna central station (VIE central) that there is hardly any evidence that this project will foster regional convergence. For GDP the correlation is rather small (-0.04) and for employment it is even negative (-0.09). The Semmering tunnel (SBT) seems to do much better in terms of fostering the convergence between regions. The correlation for GDP and GDP per capita is negative (-0.35) and the correlation between induced employment effects and the unemployment rate is positive $(+0.2)$.

\section{Summary}

This paper developed a new regional approach to evaluate investments in new traffic infrastructure in Austria. The main model concentrates on a spatial econometric approach that captures the benefits of new infrastructure via the improvement of the accessibility of regions. Mobility is one key elements in modern market economies and therefore higher accessibility leads to a more efficient allocation of resources, which triggers productivity gains and stimulates growth.

This paper concentrates on railway traffic infrastructure of 2 larger rail projects in Austria: The new Vienna central station and the Semmering tunnel. Whereas the new Vienna central station mainly benefits regions in the north and east of Austria, the Semmering tunnel mainly affects regions in the East and South of Austria. Even though both projects have similar overall effects on national growth, the geographical pattern of regional effects differs substantially. The Vienna central station shows no evidence that it will foster regional convergence. This follows from the fact that the beneficiaries of this project are the Vienna region and its neighbors, which already have low unemployment and are high income regions in Austria. In contrast to that the beneficiaries of the Semmering tunnel are structurally weak regions located in the east and Southeast of Austria. As a consequence, the tunnel project will increase regional convergence. This can be concluded for the 3 major economic indicators: GDP, employment and firm growth.

Thus, although the national effects of new infrastructure investment might be similar, the implications for regional policy makers can be quite different. Therefore our regional spatial model demonstrates, that these questions of infrastructure investments can be successfully modelled to evaluate the impact for weak regions and growth in the long run. Regional accessibility 
Review of Economic Analysis 2 (2010) 73-85
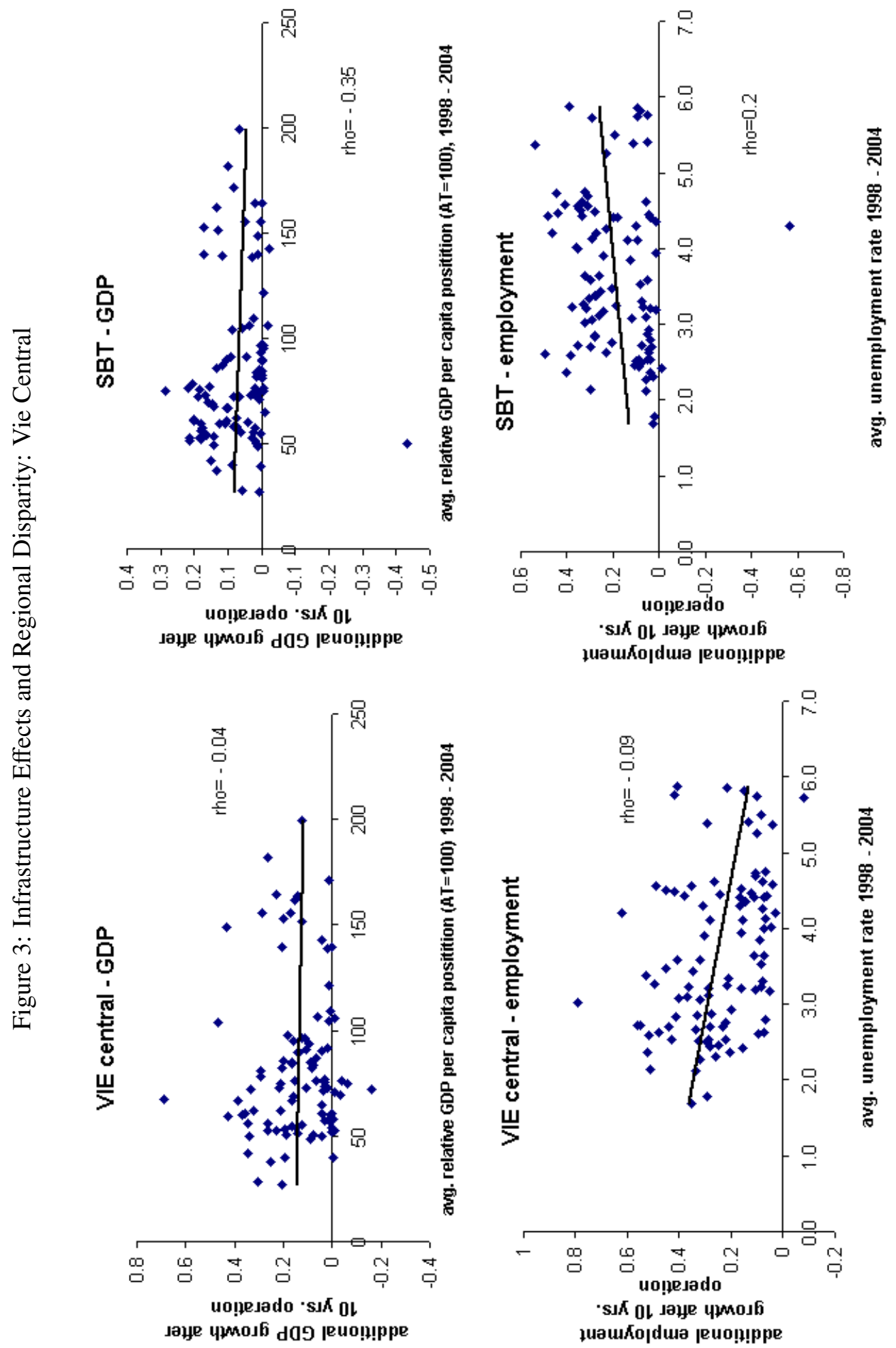
POLASEK, SCHWARZBAUER, SELLNER Effects of new railway infrastructure

models are a valuable tool for economic policy makers as well as for regional and infrastructure economists.

\section{References}

Aschauer, D.A. (1989), Is public expenditure productive? Journal of Monetary Economics 23, 177-200.

Baum, H. and Kurte, J. (2001), Transport and economic development. Paper prepared for the European Conference of Ministers of Transport (ECMT), Round Table 119, CEMT/RE/TR (2001)5.

Broecker, J., Meyer, R., Schneekloth, N., Schuermann, C., Spiekermann, K. and Wegener, M. (2004), Modelling the Socio-Economic and Spatial Impacts of EU Transport Policy Deliverable D6 of IASON (Integrated Appraisal of Spatial Economic and Network Effects of Transport Investments and Policies). Kiel, Christian Albrechts University of Kiel.

European Conference of Ministers of Transport (2000): Assessing the Benefits of Transport (pre-publication version). Paris.

Geweke, J. (1993), Bayesian Treatment of the Independent Student- $t$ Linear Model, Journal of Applied Econometrics 8, s19-s40.

Krugman P. (1991), Increasing Returns and Economic Geography, Journal of Political Economy 99, 843-499.

Lall, S.V. (2007), Infrastructure and regional growth, growth dynamics and policy relevance for India. Annals of Regional Science 41, 581-599.

LeSage, J.P. and Parent, O. (2006), Bayesian Model Averaging for Spatial Econometric Models, Available at SSRN: http://ssrn.com/abstract $=924608$.

LeSage, J. P. (1997), Bayesian Estimation of Spatial Autoregressive Models. International Regional Science Review 20, 113-129.

Polasek W. (2005), Improving Train Network until 2020: A stimulus for regional growth? unpublished manuscript, IHS Wien.

Polasek, W. and Schwarzbauer, W. (2006), Traffic Accessibility and the Effect on Firms and Population in 99 Austrian Regions, IHS Economic Series No. 198, November.

Schuermann, C. and Talaat, A. (2000), Towards a European Peripherality Index. Final Report for DG Regional Policy of the European Commission, Brussels.

Spiekermann, K. and Neubauer, J. (2002), European Accessibility and Peripherality: Concepts, Models and Indicators, Nordregio Working Paper No. 9.

Steininger, K., Schmid, C., Braumann, A. (2007), New Primary Road Transport Infrastructure and the Spatial Distribution of Growth: A Spatial CGE Analysis for an Eastern Austrian Border Region, paper presented at the Annual Meeting of the Austrian Economic Association (NOeG) Klagenfurt, Austria. 